\title{
Fragmentation Mechanisms of Oxidized Peptides Elucidated by SID, RRKM Modeling, and Molecular Dynamics
}

\author{
Jeffrey M. Spraggins, ${ }^{a}$ Julie A. Lloyd, ${ }^{a}$ Murray V. Johnston, ${ }^{a}$ \\ Julia Laskin, and Douglas P. Ridge ${ }^{a}$ \\ ${ }^{a}$ Department of Chemistry and Biochemistry, University of Delaware, Newark, Delaware, USA \\ b Pacific Northwest National Laboratory, Richland, Washington, USA
}

The gas-phase fragmentation reactions of singly charged angiotensin II (AngII, DR ${ }^{+}$VYIHPF) and the ozonolysis products AngII+O (DR $\left.{ }^{+} Y^{*} \mathrm{IHPF}\right)$, AngII+3O $\left(\mathrm{DR}^{+} \mathrm{VYIH}^{*} \mathrm{PF}\right)$, and AngII $+4 \mathrm{O}\left(\mathrm{DR}^{+} \mathrm{VY}^{*} \mathrm{IH} \mathrm{H}^{*} \mathrm{PF}\right)$ were studied using SID FT-ICR mass spectrometry, RRKM modeling, and molecular dynamics. Oxidation of Tyr (AngII $+\mathrm{O})$ leads to a low-energy charge-remote selective fragmentation channel resulting in the $\mathbf{b}_{4}+\mathrm{O}$ fragment ion. Modification of His (AngII $+3 \mathrm{O}$ and AngII $+4 \mathrm{O}$ ) leads to a series of new selective dissociation channels. For AngII $+3 \mathrm{O}$ and AngII $+4 \mathrm{O}$, the formation of $[\mathrm{MH}+3 \mathrm{O}]^{+}-45$ and $[\mathrm{MH}+3 \mathrm{O}]^{+}-71$ are driven by charge-remote processes while it is suggested that $\mathbf{b}_{5}$ and $[\mathrm{MH}+\mathbf{3 O}]^{+} \mathbf{- 8 8}$ fragments are a result of charge-directed reactions. Energy-resolved SID experiments and RRKM modeling provide threshold energies and activation entropies for the lowest energy fragmentation channel for each of the parent ions. Fragmentation of the ozonolysis products was found to be controlled by entropic effects. Mechanisms are proposed for each of the new dissociation pathways based on the energies and entropies of activation and parent ion conformations sampled using molecular dynamics. (J Am Soc Mass Spectrom 2009, 20, 1579-1592) (c) 2009 Published by Elsevier Inc. on behalf of American Society for Mass Spectrometry

$\mathrm{T}$ The possibility of detrimental human health and environmental effects from ozone exposure [1-27] has prompted a number of studies pertaining to ozone oxidation of amino acids and peptides [28-32]. Spectroscopic studies found Met, Trp, Tyr, Cys, His, and Phe to be the most vulnerable to oxidation after exposure to ozone in aqueous solution [29-32]. In addition, ESI MS/MS experiments of the ozone reaction products of single amino acids and small peptides were done to determine the resulting product structures of the oxidized amino acid residues [28].

A recent study has addressed the rates of ozone oxidation and the mechanism of ozonolysis in aqueous solution for angiotensin II (DRVYIHPF) and the analogs DRVYIAPA and DRVAIHPA using mass spectrometry [33]. Although other minor oxidation products were observed, the primary reaction products following exposure to ozone were found to result in the addition of one oxygen atom to Tyr $(\mathrm{AngII}+\mathrm{O})$ and three oxygen atoms to His (AngII+3O). MS/MS spectra for the oxidation products exhibited some fragmentation processes that were distinct from the usual patterns observed in peptides with acidic amino acid side chains

Address reprint requests to Dr. D. P. Ridge, 106 Lamont DuPont Laboratory, University of Delaware, Newark, DE 19711, USA. E-mail: dougr@ udel.edu
[34]. It was important to establish that the observed fragment ions were consistent with suggested structures of the oxidized peptides. The present examination of the energetics and dynamics of the collisional fragmentation of oxidized peptides is intended to provide a basis for relating postulated structures of the oxidized peptides to the observed MS/MS differences. Energetic and dynamic results of the kind reported here have not been previously available for oxidized peptides, so the results may facilitate studies of peptide oxidation by improving our ability to assign structures to the resulting oxidized peptides.

Elucidation of the collisional fragmentation patterns of oxidized peptides also pertains to a protein characterization method referred to as oxidative footprinting [35-47]. In this technique, three-dimensional structures and conformational changes of proteins and protein complexes are examined by observing the oxidation reactivity of the solvent accessible amino acid side chains. The experiment is designed so that the time scale of oxidation exposure is shorter than the time necessary for major structural rearrangement. Following the oxidation reaction, the target protein is then analyzed using traditional bottom-up proteomic methods in which the target undergoes enzymatic cleavage and the resulting peptides are sequenced using MS/ MS. Specific information on the energetics and dynam- 
ics of oxidized peptide fragmentation could be useful in using collisional fragmentation of digest fragments to locate oxidation sites.

Qualitative studies of collisional fragmentation processes, even when the collision energy is varied, do not provide such important energetic and dynamic quantities as threshold energies and entropies of activation. These quantities can only come from measurements of rate constants as a function of internal energy. The results reported here were obtained using a unique method, which combines energy-resolved surface induced dissociation (SID) and Fourier transform ion cyclotron resonance mass spectrometry (FT-ICR MS). A packet of ions of selected translational energy collides with a prepared surface at a known collision time. The collisional reaction products are caught in the FT-ICR MS trap and sampled at known reaction times. The determination of fragmentation rate constants as a function of internal energy, and hence threshold energies and activation entropies from the resulting data, has been described [48]. The methodology has been applied to the dissociation reactions of a number of model peptides providing a context for the present results [49-59]. Particularly relevant are results for the model peptides LDIFSDF, LDIFSDFR, RLDIFSDF, and LEIFSEFR [56], as well as angiotensin II (DRVYIHPF) and the relative analogs RVYIHPF, RVYIHAF, and RVYIHDF [55]. These studies provide particular insight into selective charge-remote fragmentations involving aspartic acid amino acid residues. Dissociation thresholds $\left(E_{0}\right)$ for charge-remote selective cleavages involving aspartic acid were found to be similar to $E_{0}$ for nonselective charge-directed dissociation pathways. In addition, large negative entropy values are observed for peptides with arginine residues due to the extensive rearrangements associated with selective fragmentation mechanisms. Similarly, arginine containing peptides with methionine sulfoxide modifications were found to fragment selectively at the methionine sulfoxide in a charge-remote process associated with a large negative activation entropy. Given the structures postulated for the oxidized peptides, charge-remote mechanisms might account for several of the unusual selective fragment ions observed for the ozonolysis reaction products of angiotensin II. In the present study when a negative entropy of activation was observed, suggesting a constrained transition-state, molecular dynamics calculations were done to probe primary ion conformations for the proposed structures of the oxidation products that could lead to the observed fragmentation patterns. The activation entropy and the molecular dynamics thus provided constraints on the proposed mechanism that strengthen the validity of the assigned oxidized peptide structure.

Applicable to the field of mass spectrometry for the analysis of both environmentally significant biomolecular ozonolysis products and bioanalytically significant protein-footprinting experiments, this study aims to build on the current literature by addressing the need for understanding gas-phase dissociation mechanisms of oxidized peptides during MS/MS experiments. Our focus is centered on how oxidative stress, resulting in modification to Tyr and His residues, affect selective fragmentation patterns of angiotensin II from an energetic and mechanistic perspective.

\section{Experimental}

Angiotensin II (DRVYIHPF) was purchased from Sigma-Aldrich (St. Louis, MO) and HPLC grade acetonitrile and methanol were purchased from Fisher Scientific (Fair Lawn, NJ). Aqueous peptide solutions $(\sim 143$ $\mu \mathrm{M})$ were prepared using deionized water (Millipore, Bedford, MA). Oxidation reactions were conducted by flowing ozone over peptide solutions for up to $21 \mathrm{~min}$ with a flow rate of $\sim 1.2 \mathrm{~L} / \mathrm{min}$. Ozone was generated using an ozone generator model PZ5 (Prozone International, Inc., Huntsville, Al). Peptide solutions were diluted 1:1 with methanol or acetonitrile for electrospray experiments.

Analysis was done using a specially fabricated 6T FT-ICR mass spectrometer (Pacific Northwest National Laboratory, Richland, WA). Ions are produced using electrospray ionization (ESI emitter, $2.2 \mathrm{kV}$ ) at atmospheric pressure and enter through a heated stainless steel capillary $(270 \mathrm{~V})$. An ion funnel [60] is then used to efficiently transfer the ions to the high vacuum region of the instrument where they pass through a series of quadrupoles used for collisional focusing, mass selection and ion accumulation. The front plate of the funnel is kept at $270 \mathrm{~V}$ while the back plate is set to $25-35 \mathrm{~V}$. The dc offsets for the three quadrupoles are set to 15-25, 5-10, and 2-6 V, respectively. Typical accumulation times range from 0.1 to $0.3 \mathrm{~s}$ and is done at elevated pressure $\left(2 \times 10^{-3}\right.$ Torr $)$ to allow internally excited ions to collisionally relax before entering the ICR cell. Ions are then extracted from the accumulation quadrupole and enter the ICR cell where they collide with the SID surface in MS/MS experiments. After collision, ions are captured by raising the trapping potentials $(10-20 \mathrm{~V})$. Ion collision energy is determined by the difference in potential between the accumulation quadrupole and the rear trapping plate of the ICR cell. SID experiments were done using a surface composed of a $2 \mu \mathrm{m}$ film of carbon vapor deposited diamond on a titanium surface prepared by P1 Diamond Inc. (Santa Clara, CA). A reaction delay of $1 \mathrm{~s}$ was used for fragmentation reactions over a range of collision energies from 23 to $81 \mathrm{eV}$ using $2 \mathrm{eV}$ increments. Energy-resolved fragmentation efficiency curves were generated from experimental mass spectra by plotting the relative abundance of primary ions and the resulting fragment ions as a function of collision energy. A more detailed description of the instrument can be found elsewhere [61]. Given the known structures of the precursor ions, most of the fragments can be unambiguously identified from their mass numbers. We note, however, that the agreement between the observed and theoretical fragment 
masses is consistent with the estimated 5 ppm accuracy of the calibrated mass scale of the SID spectra.

\section{RRKM Modeling}

Collision energy-resolved fragmentation efficiency curves (FECs) were modeled using a previously discussed RRKM-based method [62, 63]. Two dissociation rate constants were used for the total ion decomposition to account for the slow and fast fragmentation, as indicated schematically below:

$\mathrm{MH}^{+}$

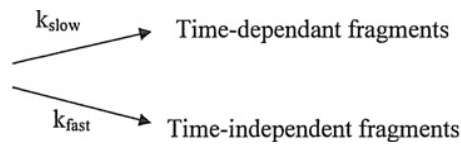

$\mathrm{k}_{\text {total }}=\mathrm{k}_{\text {slow }}+\mathrm{k}_{\text {fast }}$

Microcanonical rate constants as a function of internal energy for the slow channel were calculated using the RRKM expression. For the fast reaction pathway the rate-energy dependence is very sharp and is best described by a step-function originating from the assumed threshold energy [57].

Fragmentation probability as a function of the internal energy of the primary ion and the experimental observation time $\left(t_{r}\right), F\left(E, t_{r}\right)$, is given by:

$$
F\left(E, t_{r}\right)=e^{-\left(k_{\text {total }}(E)-k_{\text {rad }}\right) t_{r}}
$$

where $\mathrm{krad}$ is the rate constant for radiative cooling of the excited ion. The energy deposition function was described by the following analytical expression:

$$
P\left(E, E_{\text {coll }}\right)=\frac{(E-\Delta)^{l} \exp \left(-(E-\Delta) / f\left(E_{\text {coll }}\right)\right)}{C}
$$

where $l$ and $\Delta$ are parameters, $C=\Gamma(l+1)[f(E c o l l)]^{l+1}$ is a normalization factor, and $f\left(E_{\text {coll }}\right)$ has the form:

$$
f\left(E_{\text {coll }}\right)=A_{2} E_{\text {coll }}^{2}+A_{1} E_{\text {coll }}+A_{0}
$$

where $A_{0}, A_{1}$, and $A_{2}$ are parameters, and $E_{\text {coll }}$ is the collision energy. Finally, the normalized signal intensity for a particular reaction channel is given by the equation:

$$
I_{i}\left(E_{\text {coll }}\right)=\int_{0}^{\infty} F_{i}(E, t) P\left(E, E_{\text {coll }}\right) d E
$$

Collision energy-resolved survival curves were constructed using the above procedure and compared with the experimental data. The energy deposition function, based on time and energy-resolved FEC data of angiotensin II from previous studies [56], was held constant for each oxidation product. Fitting parameters included the critical energy and the activation entropy for the total decomposition of the precursor ion. The quality of the fits was confirmed using sensitivity analysis described previously [63].

Vibrational frequencies of precursor ions were obtained from the frequency model provided by Christie and coworkers [64]. Vibrational frequencies for the transition state were varied by adjusting vibrational frequencies for the transition-state which were estimated by removing one $\mathrm{C}-\mathrm{N}$ stretch (reaction coordinate) from the parent ion frequencies as well as adjusting all frequencies in the range $500-1000 \mathrm{~cm}-1$ to obtain the best fit with experimental data. The resulting frequencies were used to calculate entropies of activation at $450 \mathrm{~K}$.

\section{Molecular Dynamics Calculations}

Molecular dynamics calculations were done using the Insight II software package from Biosym Technologies (San Diego, CA). Peptides were constructed using the amino acid database of the Biopolymer module. Both the $\mathrm{N}$ - and C-terminus of all peptides were capped with hydrogen atoms and left neutral. A proton was placed on the most basic site (DR ${ }^{+}$VYIHPF) or as indicated below on a site appropriate for a particular charge driven decomposition mechanism. Peptide modification was done using the Fragment Library within the Biopolymer module. Modification to the Tyr residue was done by replacing the appropriate hydrogen atom of the side chain with a hydroxyl group while His modification was done by substituting an Ala residue for His and constructing the oxidized His* residue from Ala using aldehyde and amide functionalities. Minimization and dynamics calculations were performed using the Discover Module. Steepest decent minimization was done for 1500 iterations using the CFF91 force field. Following minimization, molecular dynamics experiments were performed at $400 \mathrm{~K}$ for 100,000 cycles (100 ps). Intramolecular hydrogen bonds were observed by turning on the hydrogen bonding feature using default parameters.

\section{Results and Discussion}

\section{Fragmentation Pathways}

Singly charged ESI FT-ICR mass spectra of angiotensin II and the oxidation products resulting from ozonolysis along with surface-induced dissociation mass spectra $(43 \mathrm{eV})$ for angiotensin II and the AngII+O, AngII $+3 \mathrm{O}$, and AngII $+4 \mathrm{O}$ adducts $-\mathrm{DR}^{+} \mathrm{VYIHPF}$, $\mathrm{DR}^{+} \mathrm{VY}^{*} \mathrm{IHPF}, \mathrm{DR}^{+} \mathrm{VYIH}{ }^{*} \mathrm{PF}$, and $\mathrm{DR}^{+} \mathrm{VY}^{*} \mathrm{IH}^{*} \mathrm{PF}$-are shown in Figure 1. The parent ion spectrum of the reaction solution shows the major oxidation products to be AngII $+\mathrm{O}$, AngII $+3 \mathrm{O}$, and AngII $+4 \mathrm{O}$ (Figure 1a). Accurate mass measurements confirmed the molecular formula of each ozonolysis adduct. SID data shows AngII and all oxidation products selectively fragment C-terminal to the aspartic acid residue (D) forming the $\mathrm{y}_{7}, \mathrm{y}_{7}+\mathrm{O}, \mathrm{y}_{7}+3 \mathrm{O}$, and $\left[\mathrm{y}_{7}+4 \mathrm{O}\right]^{+}-71$ dissociation products respectively (Figure $1 \mathrm{~b}-\mathrm{e}$ ). Selective fragmentation C-terminal to acidic residues (aspartic or glutamic acids) is typical of peptides when the number of ionizing protons is less than or equal to the number of basic sites 

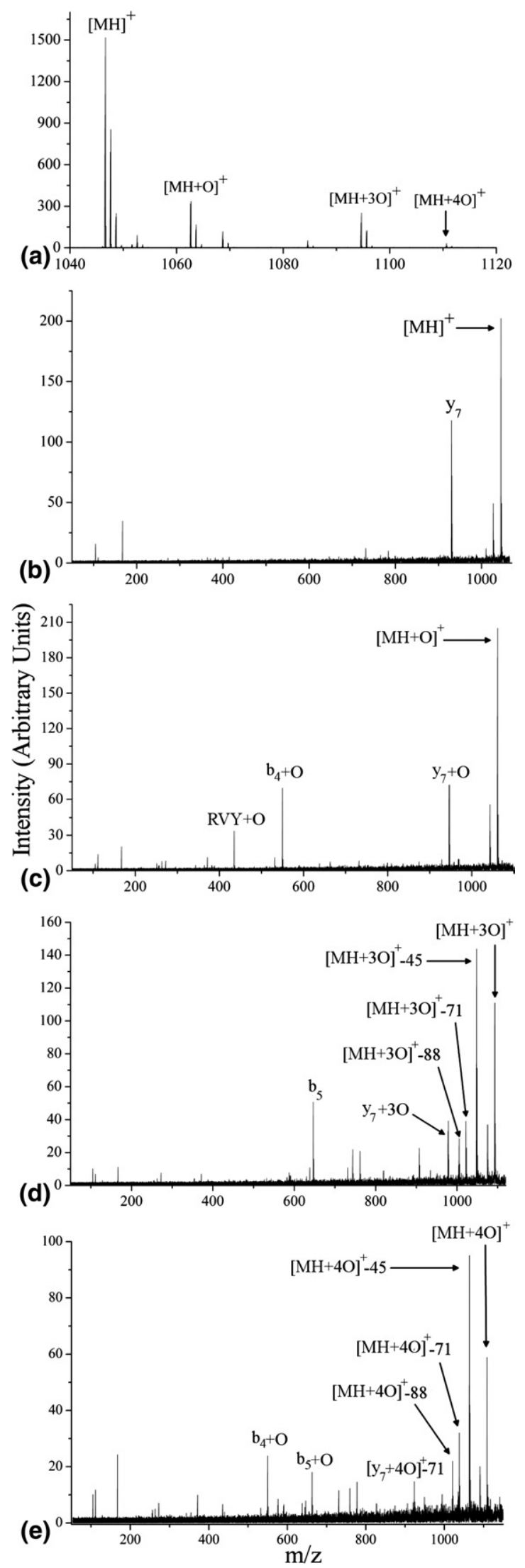

[34]. Modification to the Tyr residue, DRVY*IHPF $($ AngII $+\mathrm{O})$, results in the selective formation of the $\mathbf{b}_{4}+\mathbf{O}$ (Figure 1c) ion while oxidation of the His residue, DRVYIH*PF (AngII+3O), opens selective fragmentation channels resulting in the formation of the $[\mathrm{MH}+$ $3 \mathrm{O}]^{+}-45,[\mathrm{MH}+3 \mathrm{O}]^{+}-71, \mathrm{~b}_{5}$, and $[\mathrm{MH}+3 \mathrm{O}]^{+}-88$ ions (Figure 1d). The AngII $+4 \mathrm{O}$ oxidation product fragments to form ions associated with modification to both Tyr and His, DRVY* $\mathrm{IH}^{*} \mathrm{PF}$, including the $[\mathrm{MH}+4 \mathrm{O}]^{+}-45, \quad[\mathrm{MH}+4 \mathrm{O}]^{+}-71, \quad[\mathrm{MH}+4 \mathrm{O}]^{+}-88$, $\mathbf{b}_{5}+\mathbf{O}$, and $\mathbf{b}_{4}+\mathrm{O}$ fragments (Figure 1e).

Unmodified angiotensin II selectively fragments to form the $\mathbf{y}_{7}$ ion resulting from charge-remote cleavage C-terminal to the aspartic acid residue (Figure 1b). This cleavage has been rationalized in terms of the "mobile" proton model $[65,66]$. According to the model, arginine $(\mathrm{R})$, being the most basic site on the molecule, sequesters the single ionizing proton preventing unselective charge-directed fragmentations at low collision energies. With the charge on the guanidine functionality of the $\mathrm{Arg}^{+}$side chain, the acidic side chain of aspartic acid can induce selective fragmentation through interaction with the peptide backbone. This common dissociation pathway has been described mechanistically in a number of studies [65-71]. According to one frequently proposed charge-remote fragmentation mechanism involving Asp residues, the hydroxyl hydrogen of the aspartic acid side chain can hydrogen bond with the carbonyl oxygen of the peptide backbone promoting a cis-1,2-elimination reaction leading to backbone cleavage C-terminal to the acidic side-chain [66-68, 71]. In this mechanism, the Asp residue plays no part in the solvation of the charge sequestered on the Arg sidechain (Scheme 1a). Alternatively, others have proposed that the selective fragmentation C-terminal to aspartic acid is driven by the formation of a salt bridge between the protonated Arg residue and the Asp side chain [66, $69,70]$. This mechanism is still charge-remote with the proton sequestered at the guanidine of the $\mathrm{Arg}^{+}$residue, however, the charge is solvated by the Asp side chain resulting in an intramolecular salt-bridge intermediate (Scheme $\mathbf{1 b}$ ). In both cases, the charge remains with the protonated $\mathrm{Arg}^{+}$residue which is C-terminal to the dissociated peptide bond, resulting in a y-type fragment ion.

Aside from the $\mathbf{y}_{7}$ fragment, the SID spectrum of AngII also shows a significant peak resulting from the loss of water from the parent ion $\left([\mathbf{M H}]^{+}-\mathbf{H}_{2} \mathbf{O}\right)$. Additional peaks are a result of minor non-selective fragment ions.

Figure 1. ESI FT-CR mass spectra of (a) AngII and the oxidation products resulting from reaction with ozone, (b) the $43 \mathrm{eV}$ SID spectrum of unmodified AngII $\left([\mathrm{MH}]^{+}\right)$, (c) the $43 \mathrm{eV}$ SID spectrum of AngII $+\mathrm{O}$ oxidation product $\left([\mathrm{MH}+\mathrm{O}]^{+}\right),(\mathrm{d})$ the $43 \mathrm{eV}$ SID spectrum of AngII $+3 \mathrm{O}$ oxidation product $\left([\mathrm{MH}+3 \mathrm{O}]^{+}\right)$, and $(\mathbf{e})$ the $43 \mathrm{eV}$ SID spectrum of AngII $+4 \mathrm{O}\left([\mathrm{MH}+4 \mathrm{O}]^{+}\right)$. 


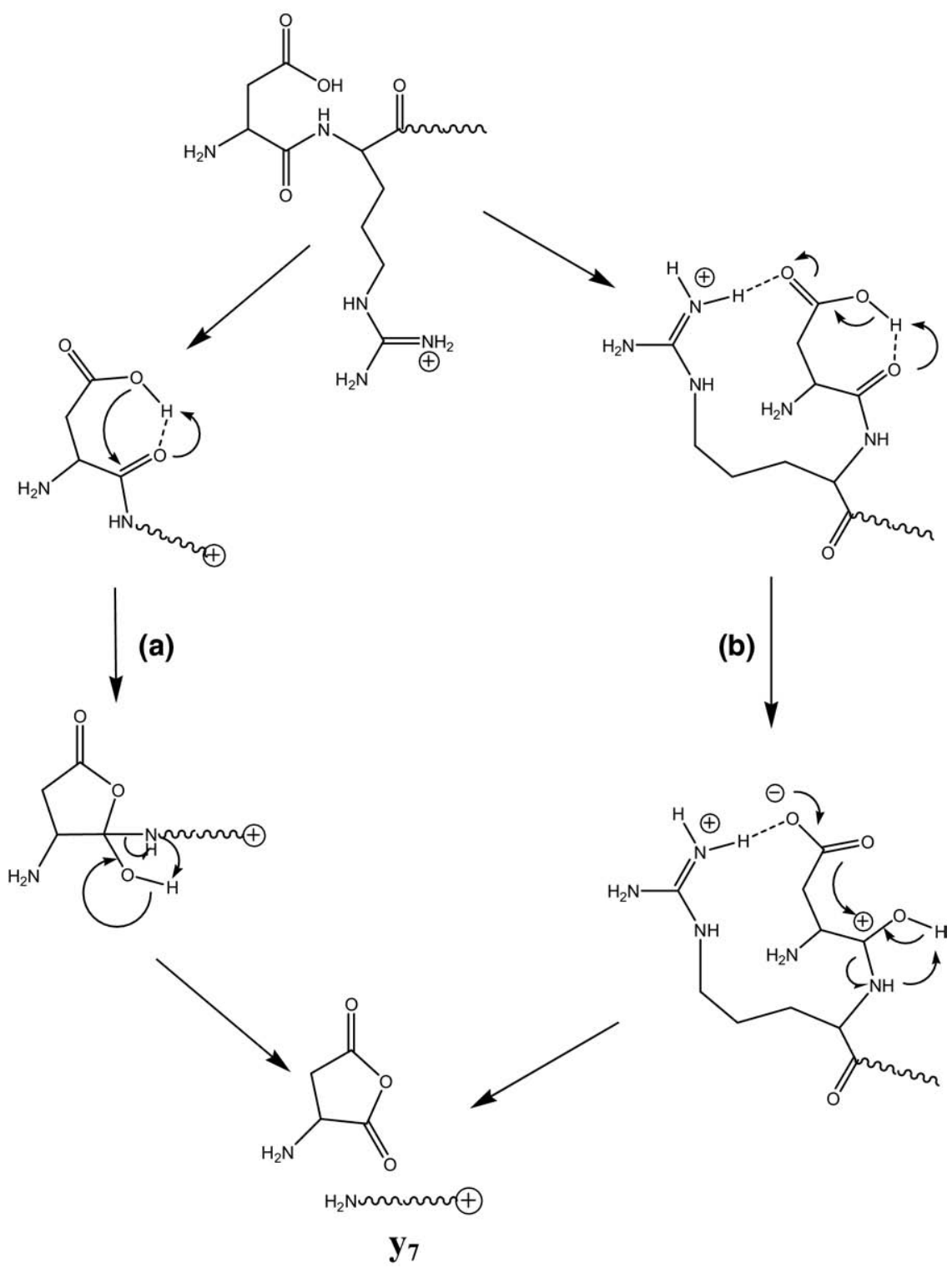

Scheme 1

SID of the AngII $+\mathrm{O}$ oxidation product results in the selective formation of the $\mathbf{y}_{7}+\mathbf{O}$ and $\mathbf{b}_{4}+\mathbf{O}$ fragment ions (Figure 1c). As observed in unmodified AngII, the most basic site of the AngII+O adduct is Arg making it the most likely site to accept the single ionizing proton resulting in charge-remote dissociation processes at low energies. The $\mathbf{y}_{7}+\mathbf{O}$ ion, just as it is in unmodified AngII, is driven by the interaction between the Asp side chain and the peptide backbone. Addition of one oxygen atom in the ozonolysis of AngII results from the oxidation of Tyr forming 3,4- or 2,4-dihydroxyphenylalanine [28]. The additional hydroxyl group of the modified Tyr* residue can mimic aspartic acid by interacting with the peptide backbone C-terminal to the $\mathrm{Tyr}^{*}$ residue resulting in chargeremote dissociation of the peptide bond between Tyr* and Ile. This is shown in Scheme 2 and results in the formation of the $\mathbf{b}_{\mathbf{4}}+\mathbf{O}$ fragment ion. This mechanism parallels the process shown in Scheme 1a for the formation of the $\mathbf{y}_{\mathbf{7}}$ fragment. It is noteworthy that the Scheme $\mathbf{2}$ mechanism requires oxidation of the Tyr at the 2-position forming the 2,4-dihydroxyphenylalanine oxidation reaction product. Due to steric constraints, a hydroxyl group at the 3-position could not interact with the peptide backbone C-terminal to $\mathrm{Tyr}^{*}$.

The facility of the selective $\mathbf{b}_{4}+\mathbf{O}$ cleavage is pertinent to the relative importance of the two mechanisms shown in Scheme $\mathbf{1 a}$ and $\mathbf{b}$ for charge-remote processes involving aspartic acid. The modified $\mathrm{Tyr}^{*}$ residue, similarly to aspartic acid, can drive C-terminal chargeremote dissociation mechanisms at low internal energies. However, unlike the Asp residue, $\mathrm{Tyr}^{*}$ cannot form a salt bride with the protonated $\mathrm{Arg}^{+}$residue suggesting that the salt-bridge intermediate is unnecessary for fragmentation C-terminal to Asp residues.

Other ions present in the $43 \mathrm{eV}$ SID spectrum of AngII $+\mathrm{O}$ are the loss of water $\left([\mathrm{MH}+\mathrm{O}]^{+}-\mathbf{H}_{2} \mathrm{O}\right)$, the 


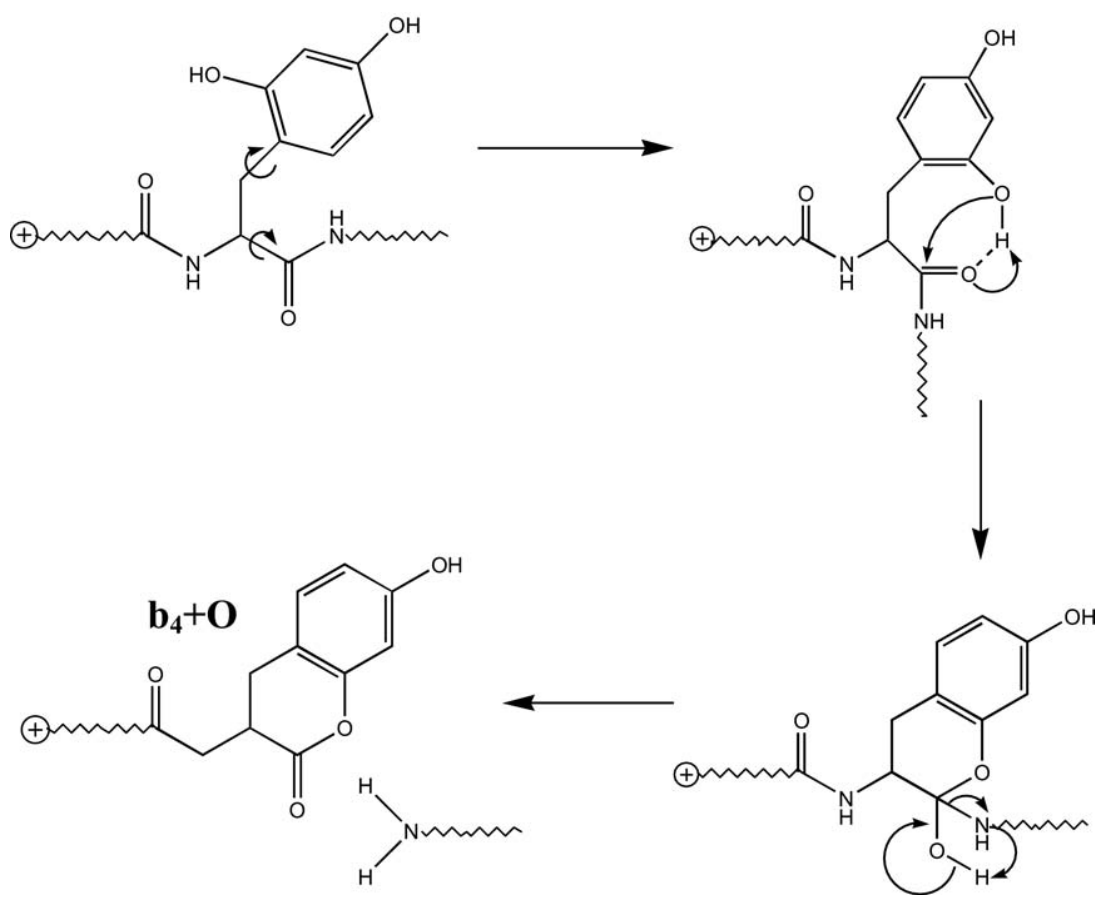

Scheme 2

internal fragment $\mathbf{R V Y}+\mathbf{O}$, and minor non-selective fragment ions.

Fragmentation of the AngII $+3 \mathrm{O}$ oxidation product results in the selective formation of the $\mathrm{y}_{7}+3 \mathrm{O},[\mathrm{MH}+$ $3 \mathrm{O}]^{+}-45,[\mathrm{MH}+3 \mathrm{O}]^{+}-71, \mathrm{~b}_{5}$, and $[\mathrm{MH}+3 \mathrm{O}]^{+}-88$ ions (Figure 1d). Fragmentation patterns using SID are consistent with previous studies that have shown the AngII +30 ozonolysis product to stem primarily from oxidation of the His residue in which three oxygen atoms are inserted into the side chain, opening the His ring, finally resulting in the 2-amino-4-oxo-4-(3formylureido)butanoic acid structure [28]. The most basic site on the DRVYIH*PF is still the Arg residue, however, the modified His* side chain is also capable of delocalizing the charge associated with protonation and might compete for the single ionizing proton. As in the case of unmodified angiotensin II, the $y_{7}+30$ fragmentation pathway is a charge remote process resulting from acidic interaction between the hydroxyl hydrogen of the aspartic acid side chain and the peptide backbone with the charge localized on either the Arg or the His* residues.

Scheme 3 shows the proposed charge-remote mechanisms for the formation of the $[\mathrm{MH}+3 \mathrm{O}]^{+}-45$ and $[\mathrm{MH}+3 \mathrm{O}]^{+}-\mathbf{7 1}$ fragment ions. With the singly ionizing proton sequestered by the $\mathrm{Arg}^{+}$residue, intramolecular hydrogen bonding can occur within the His* side chain forming a hydrogen bond between the hydrogen atom of the first amide group of the His* side chain relative to the peptide backbone and the formyl oxygen atom of the His* side chain. The proton can then be transferred, breaking the peptide-like bond of the His* side chain between the second carbonyl carbon atom and the second amide nitrogen from the peptide backbone, resulting in the loss of neutral $\mathrm{CH}_{3} \mathrm{NO}$ and the formation of the $[\mathrm{MH}+3 \mathrm{O}]^{+}-45$ fragment ion. Similarly, a hydrogen bond can form within the His* side chain between the hydrogen atom of the second amide group and the oxygen atom of the first carbonyl group from the peptide backbone. This interaction drives the dissociation of the peptide-like bond between the nitrogen atom of the first amide nitrogen from the peptide backbone and the carbon atom of the second carbonyl group. This fragmentation pathway producing the $[\mathrm{MH}+3 \mathrm{O}]^{+}-71$ ion loses neutral $\mathrm{C}_{2} \mathrm{HNO}_{2}$.

As mentioned above, the relative basicity of oxidized His* allows it to compete with Arg for the single ionizing proton. It is proposed that as the collision energy increases sufficient internal energy becomes available to transfer the ionizing proton to the modified His* side chain opening charge-directed fragmentation channels. Scheme 4 outlines the suggested mechanisms for the charge-directed formation of the $b_{5}$ and $[\mathrm{MH}+3 \mathrm{O}]^{+}-\mathbf{8 8}$ fragment ions. Formation of the $\mathbf{b}_{5}$ secondary ion is driven by protonation of the first carbonyl oxygen of the His* side chain relative to the peptide backbone. The proton can then be transferred to the amide nitrogen of the peptide backbone $\mathrm{N}$-terminal to the oxidized His* residue following the formation of a five member ring and cleavage of the peptide bond between Ile and His*. The C-terminal side of the peptide relative to the dissociated peptide bond is lost as a neutral and the charge is carried by the N-terminal fragment as a tertiary carbocation within the newly formed oxazolone ring structure resulting in a b-type ion [72]. On the other hand, proton transfer to the third 

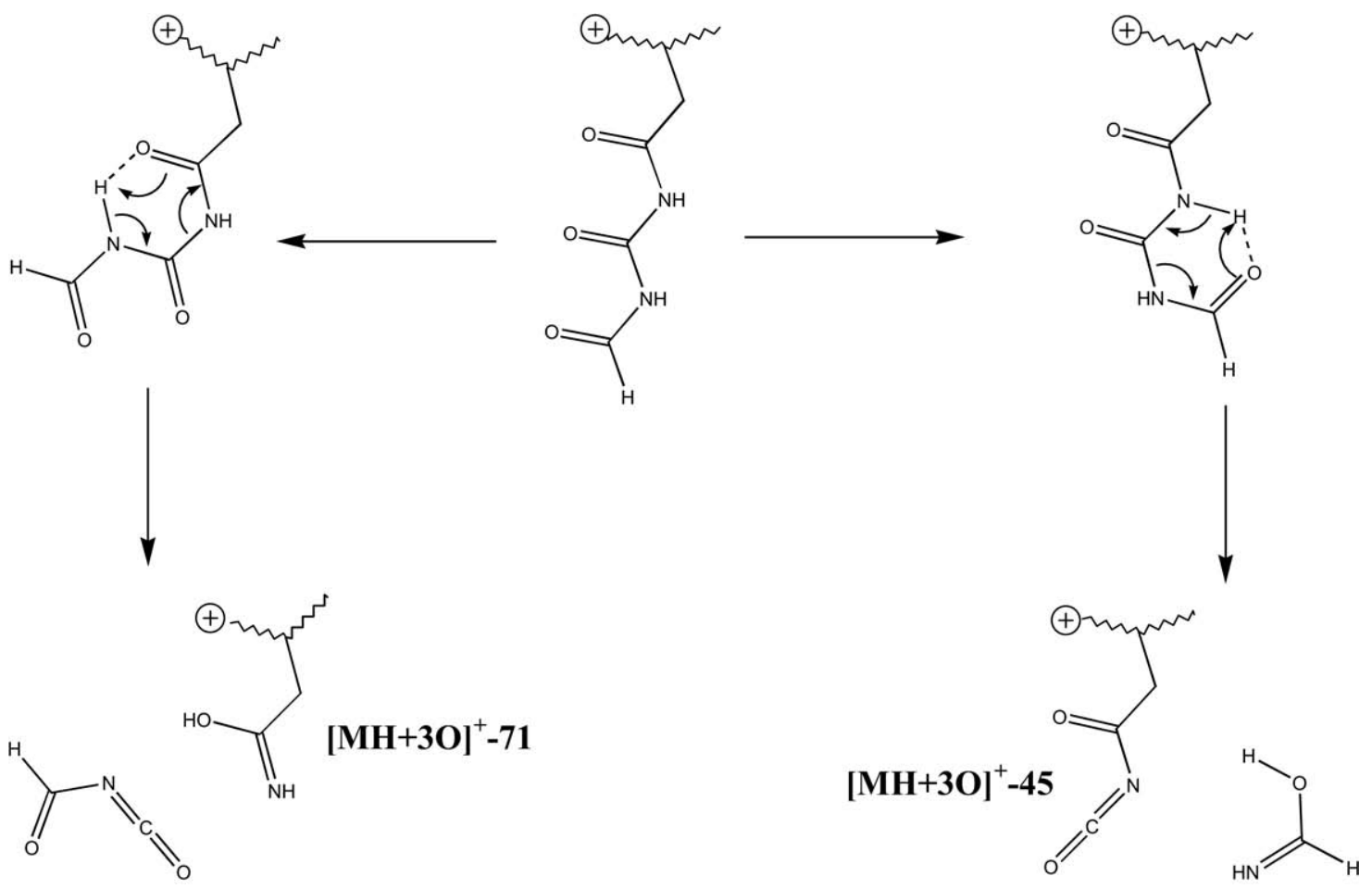

Scheme 3

carbonyl oxygen atom of the $\mathrm{His}^{*}$ residue drives the formation of the $[\mathrm{MH}+\mathbf{3 O}]^{+}-\mathbf{8 8}$ fragment ion. Hydrogen bond formation between the additional proton and the first amide nitrogen of the modified His* residue relative to the peptide backbone promotes cleavage of the peptide-like bond between the first carbonyl carbon atom relative to the peptide backbone and the protonated amide nitrogen following the formation of a fivemember ring involving the carbonyl functional group C-terminal to the oxidized His* residue. The charge is carried by the peptide as a tertiary carbocation within the newly formed oxazolone ring while the His* side chain is lost as the neutral $\mathrm{C}_{2} \mathrm{H}_{4} \mathrm{~N}_{2} \mathrm{O}_{2}$ species [72]. We note that these charge-driven fragmentation mechanisms are completely analogous to the well characterized backbone fragmentation mechanisms leading to $\mathbf{b}_{\mathbf{n}}$ ions with oxazolone ring structures [72].

\section{Fragmentation Energetics}

Fragmentation energetic studies were conducted by monitoring ion signal as a function of SID collision potential with a time delay of $1 \mathrm{~s}$ between ion collision and detection. Parent ion survival curves for angiotensin II and the primary oxidation products can be found in Figure 2a. Oxidation resulting from reaction with ozone results in destabilization of the respective parent ions relative to collisional fragmentation. The collision energy needed for fragmentation decreases with increased oxidation as follows: AngII $>$ AngII $+\mathrm{O}>$ AngII $+3 \mathrm{O} /$ AngII $+4 \mathrm{O}$. This trend is evident from the shift in energy-resolved survival curves to lower colli- sion energies with increased oxidation (Figure 2a). The AngII $+3 \mathrm{O}$ and AngII $+4 \mathrm{O}$ adducts have overlapping collision-energy-resolved FECs, which suggests the lowest energy fragmentation channel of the AngII $+4 \mathrm{O}$ species is associated with oxidative modification to the His residue. The gradual shift of each of the survival curves has been shown to suggest that the dominant dissociation pathways are kinetically unfavored with large negative reaction entropies [56].

The fragment ion onset curves for unmodified angiotensin II (Figure 1b) show the minimum collision energy required to open the primary selective fragmentation channel resulting in the formation of the $\mathbf{y}_{7}$ ion to be $27 \mathrm{eV}$. This fragmentation pathway dominates until $50 \mathrm{eV}$ at which high-energy nonselective fragmentation channels associated with the transfer of the ionizing proton to the peptide backbone are unlocked. This observation of selective charge-remote fragmentation at low internal energies followed by non-selective fragment ions at high internal energies is consistent with the previously discussed mobile proton model [73].

Oxidation of the Tyr residue following ozonolysis of AngII opens the $\mathbf{b}_{4}+\mathbf{O}$ selective fragmentation pathway. The onset curves for $\mathrm{DR}^{+} \mathrm{VY}{ }^{*} \mathrm{IHPF}$ (Figure 2c) show the lowest energy fragmentation channel to be the $\mathbf{b}_{4}+\mathbf{O}$ pathway at $27 \mathrm{eV}$ with the other selective dissociation mechanism $\left(\mathrm{y}_{7}+\mathbf{O}\right)$ shifted to $35 \mathrm{eV}$. It should be noted that oxidation of Tyr has little affect on the overall peptide structure and no apparent affect on the structure of the transition-state for the $\mathbf{y}_{7}+\mathrm{O}$ dissociation reaction. Additionally, the onset energies for both the $\mathbf{b}_{4}+\mathbf{O}$ fragment in AngII $+\mathrm{O}$ and the $\mathbf{y}_{7}$ fragment in 


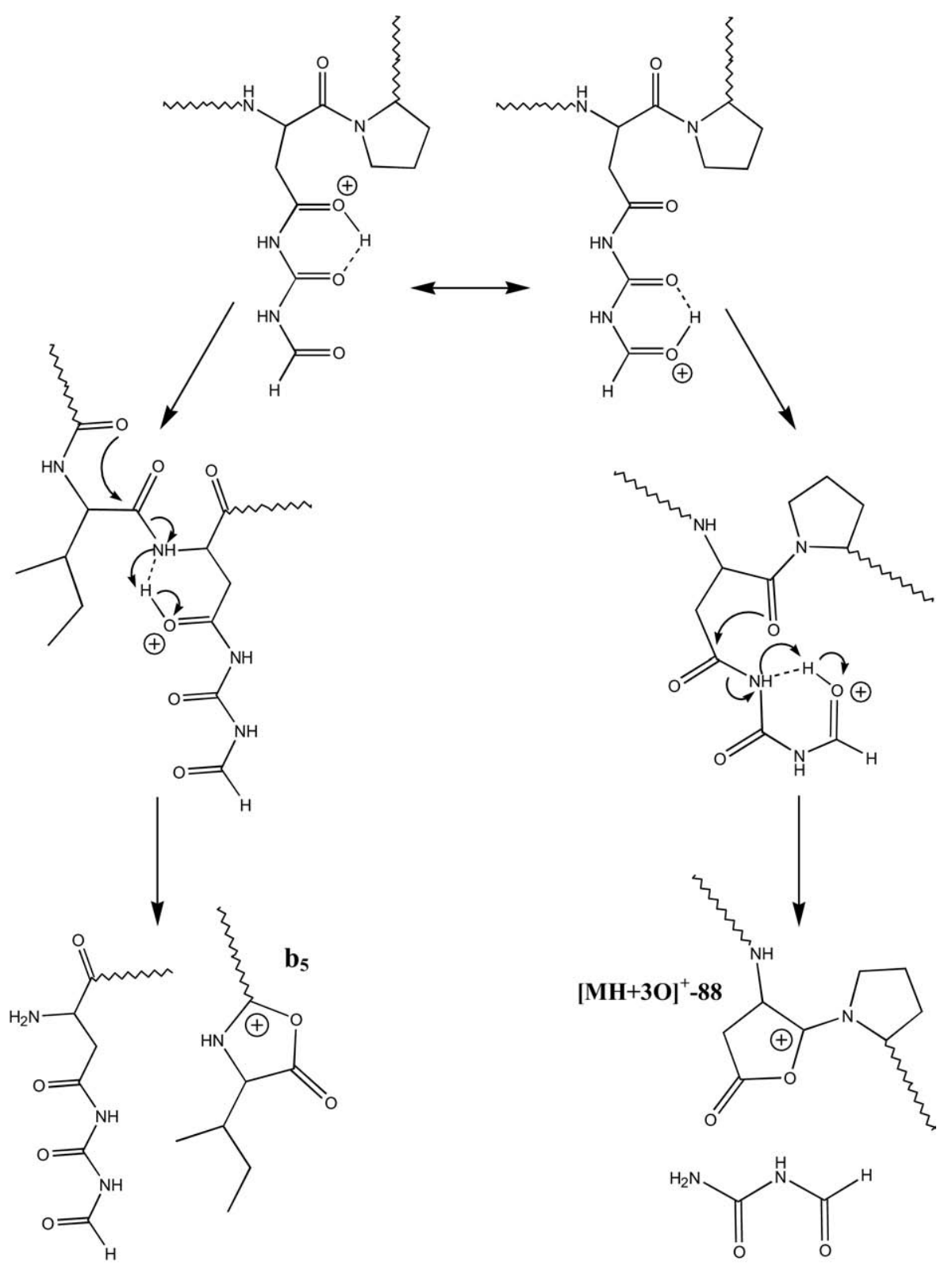

Scheme 4

unmodified AngII occur at $27 \mathrm{eV}$. This suggests the shift to higher collision energies for the $\mathbf{y}_{7}+\mathrm{O}$ fragment ion in AngII $+\mathrm{O}$, in relation to the $\mathbf{y}_{\mathbf{7}}$ fragmentation channel in unmodified AngII, is due to competition with the more entropically favorable $\mathbf{b}_{4}+\mathbf{O}$ dissociation mechanism in the oxidized form of the peptide. This is born out by the RRKM results discussed below. All other fragments appear at high collision energies driven by non-selective charge-directed pathways.

The onset curves for the fragmentation channels of AngII $+3 \mathrm{O}$ (Figure 2d) highlight a much different fate for the parent ion in comparison to unmodified AngII and AngII $+\mathrm{O}$. The onset energies of each of the primary fragment ions for the AngII $+3 \mathrm{O}$ oxidation product suggest that there are three different families of dissociation mechanisms taking place as the collision energy increases. The lowest energy pathways are the dissociation channels producing the $[\mathrm{MH}+3 \mathrm{O}]^{+}-45$ and $[\mathrm{MH}+3 \mathrm{O}]^{+}-71$ fragment ions. The $[\mathrm{MH}+3 \mathrm{O}]^{+}-45$ species is formed immediately at the lowest sampled collision energy $(23 \mathrm{eV})$, while the $[\mathrm{MH}+3 \mathrm{O}]^{+}-\mathbf{7 1}$ ion is first observed at $27 \mathrm{eV}$. The second family of curves are for the $\mathrm{b}_{5}$ and $[\mathrm{MH}+3 \mathrm{O}]^{+}-\mathbf{8 8}$ fragment ions at onset energies of 33 and $35 \mathrm{eV}$ respectively. The third family of ions includes all other fragments that appear at high collision energies resulting from nonselective chargedirected fragmentation pathways. Also observed at higher energy $(37 \mathrm{eV})$ is the $\mathbf{y}_{\mathbf{7}}+\mathbf{3 0}$ whose analogue appears at $27 \mathrm{eV}$ for unmodified AngII. As in the case of AngII $+\mathrm{O}$ this process shifts to higher energy as a result of competition with more entropically favorable fragmentation mechanisms. 


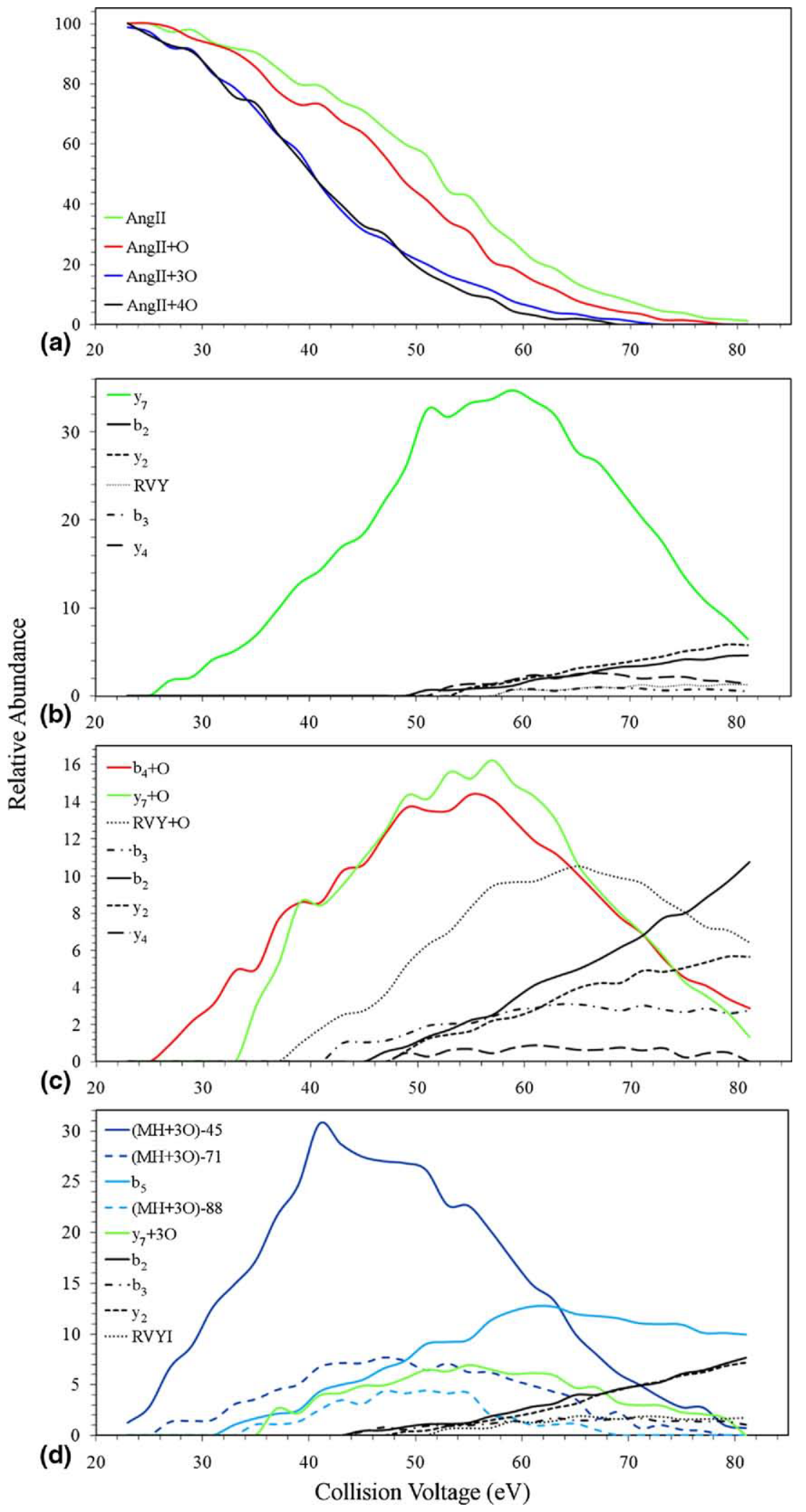

Figure 2. Energy-resolved SID FT-ICR MS data for AngII and the oxidation products resulting from ozonolysis representing (a) the parent ion survival curves for AngII, AngII $+\mathrm{O}$, AngII $+3 \mathrm{O}$, and AngII $+4 \mathrm{O}$, (b) FECs of the fragments resulting from AngII, (c) FECs of the fragments resulting from AngII $+\mathrm{O}$, and (d) FECs of the fragments resulting from AngII $+3 \mathrm{O}$. 
From a qualitative perspective, the onset curves of AngII $+3 \mathrm{O}$ describe the behavior of the extra proton as the collision energy increases. At very low energies, the proton resides on the most basic site of the molecule (Arg) so that that the first family of fragment ions results from charge-remote selective fragmentation channels $\left([\mathrm{MH}+3 \mathrm{O}]^{+}-45,[\mathrm{MH}+3 \mathrm{O}]^{+}-71\right.$, and $\left.\mathrm{y}_{7}+3 \mathrm{O}\right)$. As the internal energy increases the proton can then move to the relatively basic modified His residue (His*) opening charge-directed fragmentation pathways associated with His* $^{*}$ resulting in the second family of fragment ions $\left(\mathrm{b}_{5}\right.$ and $\left.[\mathrm{MH}+3 \mathrm{O}]^{+}-88\right)$. Finally, at high collision energies the internal energy is great enough that the proton can move to the peptide backbone allowing for nonselective charge-directed fragmentations leading to the third family of secondary ions. The onset curves are thus consistent with the proposed fragmentation mechanisms proposed above and with the mobile proton model.

\section{RRKM Modeling of Experimental Data}

Parameters giving the best fit to the parent ion survival curves are summarized in Table 1 . The reaction barrier $\left(E_{\mathrm{o}}\right)$, the pre-exponential factor $(A)$, and the activation entropy $\left(\Delta S^{\ddagger}\right)$ for the dissociation parent ions all increase with increased oxidation, that is in the order: AngII $<$ AngII $+\mathrm{O}<$ AngII $+3 \mathrm{O}<$ AngII $+4 \mathrm{O}$. The quantitative kinetic parameters thus confirm that the shift of the survival curves to lower collision energy with increasing oxidation is completely entropy controlled.

The fragmentation of each of the parent ions is dominated by a single process, particularly at low energies. For AngII, the dominant process is formation of the $\mathrm{y}_{7}$ ion, for AngII $+\mathrm{O}$ it is the $\mathrm{b}_{4}+\mathrm{O}$ ion, and for AngII $+3 \mathrm{O}$ it is the $[\mathrm{MH}+3 \mathrm{O}]^{+}-45 \mathrm{ion}$. If correct, the mechanisms proposed for these processes should therefore be consistent with the observed activation entropies. Consideration of the proposed transition states confirms that the observed activation entropy decreases as expected with the number of free rotations lost on transition-state formation. AngII with an activation entropy of $-25.9 \mathrm{cal} / \mathrm{mol} \mathrm{K}$ loses four side-chain internal rotations on formation of the transition-state for the $\mathbf{y}_{7}$ fragmentation pathway (Scheme 1a), as indicated in Scheme 5a (black arrows indicate internal rotations

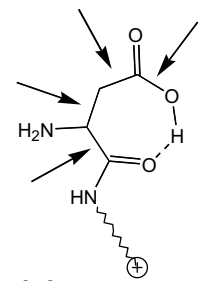

(a)

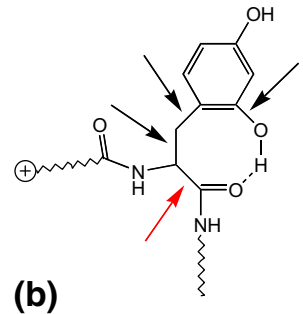

(b)

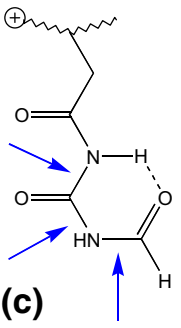

Scheme 5

lost). In comparison, the $\mathbf{b}_{\mathbf{4}}+\mathbf{O}$ dissociation pathway of AngII $+\mathrm{O}$ has a more positive entropic value $(-21.6$ $\mathrm{cal} / \mathrm{mol} \mathrm{K}$ ) associated with a transition state characterized by the loss of three side-chain internal rotations (black arrows in Scheme 5b) and one backbone rotation (red arrow in Scheme 5b). Although four total rotations are lost, the backbone rotation is a sterically hindered internal rotation making the entropic effect more positive in relation to the four free rotations lost upon formation of the transition-state of the $\mathbf{y}_{7}$ mechanism. AngII $+3 \mathrm{O}$ has the most positive activation entropy, $-17.0 \mathrm{cal} / \mathrm{mol} \mathrm{K}$ (Table 1), and formation of the transition-state leading to the $[\mathrm{MH}+3 \mathrm{O}]^{+}-45$ is associated with the loss of three amide bond rotations of the His* side chain (blue arrows in Scheme $5 \mathrm{c}$ ). The further positive shift in entropy, in relation to the transition states for the $\mathbf{y}_{7}$ and $\mathbf{b}_{4}+\mathbf{O}$ mechanisms, highlights the double-bond characteristics of the peptide-like amide bonds of the His* side chain. Delocalization of the electron cloud between the amide and carbonyl bonds does not allow for free rotation.

The entropies of activation are also pertinent to the question raised above concerning the possibility of a salt bridge mechanism (Scheme $\mathbf{1 b}$ ) for the $\mathrm{y}_{7}$ fragmentation. The salt bridge mechanism involves closing two rings simultaneously which should result in a much greater negative shift in entropy, particularly in comparison to the entropy of the $\mathbf{b}_{4}+\mathbf{O}$ mechanism than is observed.

\section{Molecular Dynamics}

Molecular dynamics experiments were done to probe how the observed fragmentation mechanisms follow from the intramolecular interactions for AngII and the

Table 1. Results of RRKM modeling of the parent ion survival curves

\begin{tabular}{lcccc}
\hline$\left[_{\mathrm{MH}+\mathrm{nO}^{+}}^{+}\right.$ & DRVYIHPF & DRVY*IHPF & DRVYIH*PF & DRVY*IH*PF \\
\hline \hline $\mathrm{m} / \mathrm{z}$ & 1046 & 1062 & 1110 & 1.21 \\
$\mathrm{E}_{0}(\mathrm{eV})$ & 1.14 & 1.20 & -17.0 & 1.24 \\
$\Delta \mathrm{S}^{\ddagger}(\mathrm{cal} / \mathrm{mol} \mathrm{K})$ & -25.9 & -21.6 & 0.07 & -15.3 \\
Relative $\mathrm{E}_{0}$ & 0 & 0.06 & $4.8 \times 10^{9}$ & 0.11 \\
$\mathrm{~A}_{\mathrm{s}} \mathrm{s}^{-1}$ & $5.6 \times 10^{7}$ & $4.8 \times 10^{8}$ & 9.7 & $1.2 \times 10^{10}$ \\
$\log (\mathrm{A})$ & 7.7 & 8.7 & 10.1 \\
\hline
\end{tabular}

$\mathrm{E}_{0}$ is the threshold energy, $\Delta \mathrm{S}^{\ddagger}$ is the entropy change for the transition state at $450 \mathrm{~K}, A$ is the pre-exponential factor at $450 \mathrm{~K}, 18.1 \%$ of each of the kinetic energy was converted to internal energy upon collision, and the radiative decay rate was set at $55 \mathrm{~s}^{-1}$ for each of the ions. 


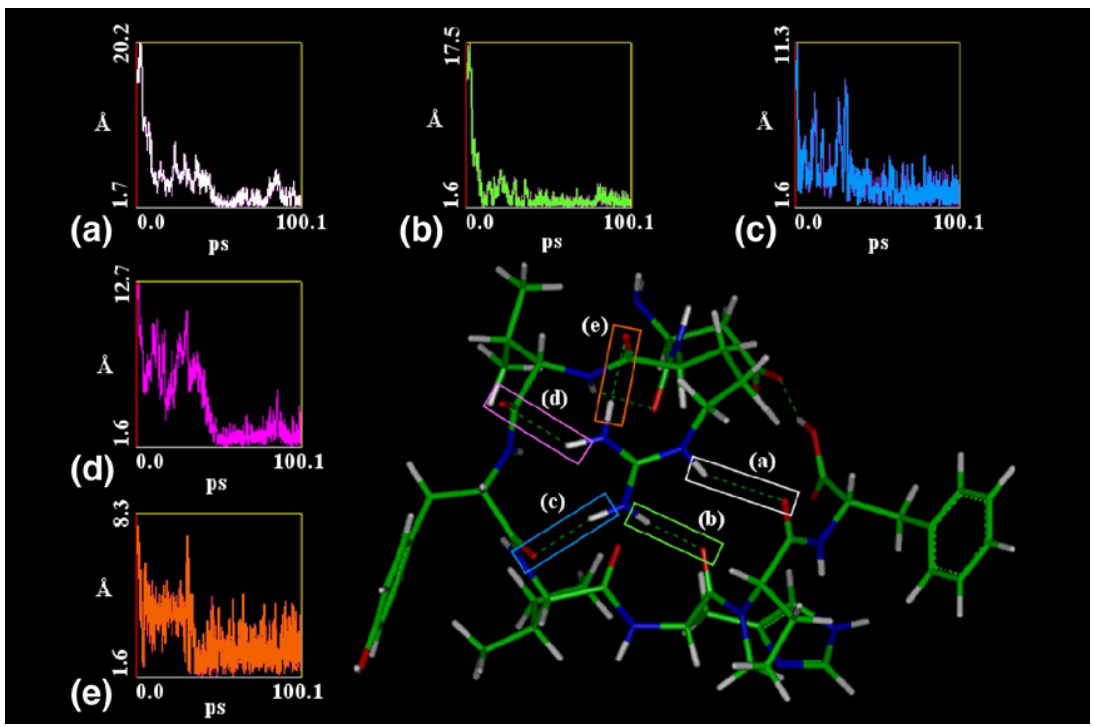

Figure 3. Molecular dynamics calculation results for AngII $+\mathrm{O}$ highlighting the delocalization of charge resulting from protonation of the Arg residue. Hydrogen bonds formed between amide hydrogen atoms of the protonated Arg residue and carbonyl oxygen atoms of the peptide backbone and the plots of bond distance $(\AA)$ as a function of time (ps) associated with each hydrogen bond are labeled (a), (b), (c), (d), and (e).

primary oxidation products AngII $+\mathrm{O}$ and $\mathrm{AngII}+3 \mathrm{O}$ before dissociation. Figures 3 and 4 provide examples of results for 100 ps calculations of $\mathrm{AngII}+\mathrm{O}$ and AngII $+3 \mathrm{O}$, respectively. Unmodified angiotensin II was first run to understand the interactions taking place between the protonated guanidine functionality of the $\mathrm{Arg}^{+}$residue and the rest of the peptide. It was apparent in all cases where the ionizing proton was placed on Arginine$\mathrm{DR}^{+}$VYIHPF, DR ${ }^{+} \mathrm{VY}^{*} \mathrm{IHPF}$, and $\mathrm{DR}^{+} \mathrm{VYIH}^{*} \mathrm{PF}-$ that the peptide delocalizes the charge by wrapping itself around the side-chain of the protonated $\mathrm{Arg}^{+}$residue forming multiple hydrogen bonds between the amide hydrogen atoms of $\mathrm{Arg}^{+}$and carbonyl oxygen atoms of the peptide backbone (Figure 3). Scheme $\mathbf{6}$ highlights the observed hydrogen bonding interactions for the molecular dynamics calculation results of AngII $+\mathrm{O}$ shown in Figure 3. Graphs of the bond distance $(\AA)$ versus time (ps) for each of the hydrogen bonds of interest (Figure 3) show

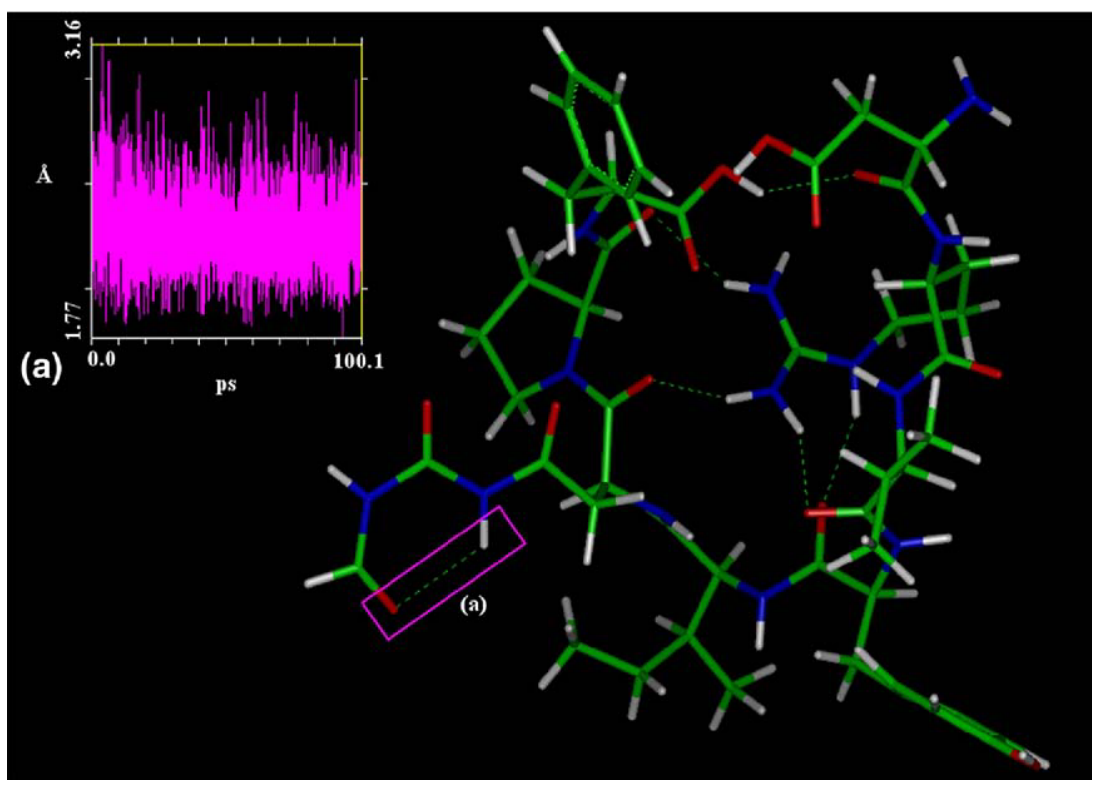

Figure 4. Molecular dynamics calculation results for the AngII $+3 \mathrm{O}$ oxidation product highlighting the hydrogen bond formed third carbonyl oxygen atom and the first amide hydrogen atom of the modified His residue. This hydrogen bond and the plot of bond distance $(\AA)$ as a function of time (ps) associated with this interaction are labeled (a). 


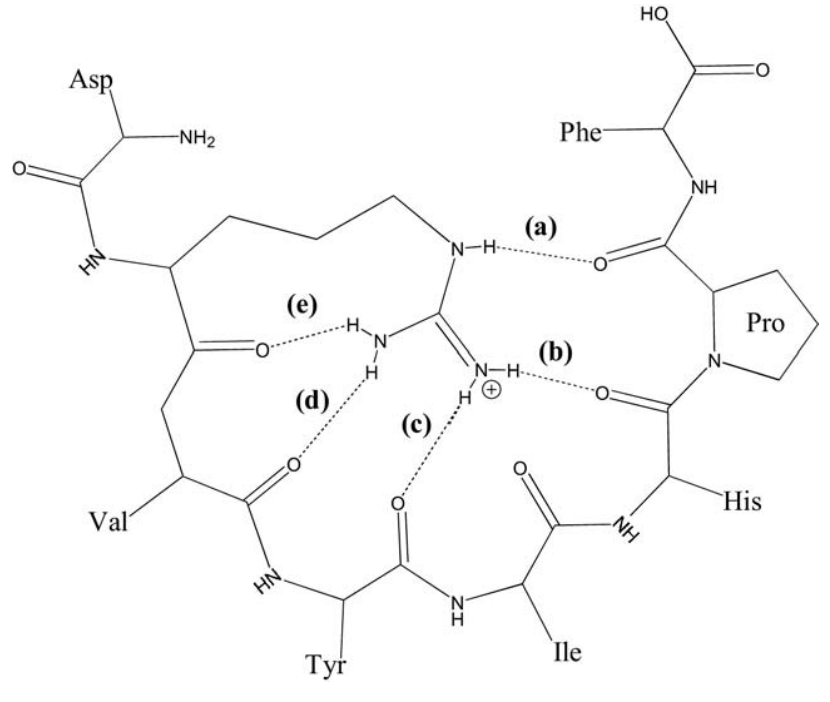

Scheme 6

that the bonds form very quickly and are very stable over the length of the experiment. At no point during the length of the experiment was a salt bridge interaction observed between the protonated Arg + residue and aspartic acid side-chain. The molecular dynamics results highlight the ability of peptides having the same number of ionizing protons as basic sites to sequester the charge making the lowest energy dissociation pathways the charge-remote fragmentation channels.

Molecular dynamics was also used to monitor the parent ion conformations for the proposed chargeremote fragmentation mechanisms shown in Schemes 2 and 3. The molecular dynamics results for $\mathrm{DR}^{+} \mathrm{VY} \mathrm{IHPF}^{*}$ show strong interaction between the hydrogen atom of the additional hydroxyl group in the 2-position and the carbonyl oxygen atom of the peptide backbone between the Tyr* and Ile residues (not shown). This interaction competes successfully with hydrogen bonding between protonated Arg and that same backbone carbonyl. The minimum hydrogen bonding distance measured during the length of the experiment was $1.92 \AA$ and hydrogen bond formed multiple times during the first 60 ps of the dynamics calculation. This intramolecular hydrogen bond is necessary for the formation of the $\mathbf{b}_{4}+\mathrm{O}$ fragment ion via the proposed mechanism in Scheme II.

Probing parent ion conformations of the AngII $+3 \mathrm{O}$ oxidation product with the ionizing proton on the Arg residue- $\mathrm{DR}^{+} \mathrm{VYIH}{ }^{*} \mathrm{PF}$ - showed very strong interactions within the modified His* residue itself. Two primary side-chain conformations emerged in the molecular dynamics experiment. The first conformation involved hydrogen bonding between the hydrogen atom of the first amide group from the peptide backbone and the oxygen atom of the formyl end group (Figure 4 ). The plot of bond distance $(\AA)$ versus time (ps) shows a very strong hydrogen bond that, once formed, is locked in for the length of the experiment only occasionally stretching beyond $2.5 \AA$. This strong interaction drives the low-energy charge-remote $[\mathrm{MH}+3 \mathrm{O}]^{+}-45$ mechanism shown in Scheme 3. Secondly, a similar strong hydrogen bond associated with the formation of the $[\mathrm{MH}+3 \mathrm{O}]^{+}-\mathbf{7 1}$ ion (Scheme 3) can form between the hydrogen atom of the second amide group and the oxygen atom of the first carbonyl relative to the peptide backbone (not shown). When formed, this interaction has a minimum bonding distance of $1.72 \AA$ and is consistently between 2.0 and $2.5 \AA$ over the length of the calculation.

\section{Conclusion}

Oxidation of Tyr and His in angiotensin II, due to exposure to ozone, leads to new, low-energy selective fragmentation channels in MS/MS experiments. A detailed approach using energy-resolved SID FT-ICR MS experiments, RRKM modeling, and molecular dynamics calculations was used to characterize the selective fragmentation channels for AngII (DR ${ }^{+}$VYIHPF) and the resulting primary ozonolysis products AngII $+\mathrm{O}$ $\left(\mathrm{DR}^{+} \mathrm{VY}^{*} \mathrm{IHPF}\right)$, AngII+3O $\left(\mathrm{DR}^{+} \mathrm{VYIH}^{*} \mathrm{PF}\right)$, and AngI+4O $\left(\mathrm{DR}^{+} \mathrm{VY}^{*} \mathrm{IH}^{*} \mathrm{PF}\right)$. This strategy was used to shed light on the mechanistic details of the unimolecular gasphase dissociation reactions of each of these singly charged species. Oxidation of Tyr opens a new lowenergy charge-remote fragmentation pathway $\left(\mathbf{b}_{4}+\mathbf{O}\right)$. The present results show that fragmentation to be consistent with oxidation of Tyr in the 2-position. Both the RRKM and molecular dynamics results support a mechanism for this fragmentation analogous to the acidic attack on the peptide backbone that takes place within Asp containing peptides with no "mobile" protons. Ozonolysis of His leads to a series of low-energy charge-remote dissociation channels $\left([\mathrm{MH}+3 \mathrm{O}]^{+}-45\right.$ and $\left.[\mathrm{MH}+3 \mathrm{O}]^{+}-71\right)$ followed by charge-directed fragmentation pathways at slightly higher energies $\left(b_{5}\right.$ and $\left.[\mathbf{M H}+30]^{+}-88\right)$. Both the RRKM and molecular dynamics results support mechanisms for the charge-remote dissociations originating with the formation of hydrogen bonds between amide hydrogens and carbonyl oxygens in the oxidized side chain. The results are thus consistent with the structure of oxidized histidine proposed in earlier studies. Note that the dominance of charge-remote pathways for all the oxidation products is consistent with the "mobile" proton model since the proton is sequestered by the Arg side chain in the oxidation products as well as in AngII itself $[65,66]$. The AngII $+4 \mathrm{O}$ adduct, containing both Tyr* and His*, shows gas-phase dissociation characteristics of both the AngII $+\mathrm{O}$ and AngII $+3 \mathrm{O}$ oxidation products. The energy thresholds for decomposition of the energy-resolved FECs show that the overall stability of the individual parent ions with respect to SID fragmentation decreases with an increase in oxidative stress (AngII $>$ AngII $+\mathrm{O}>$ AngII $+3 \mathrm{O} /$ AngII $+4 \mathrm{O}$ ). RRKM modeling gives reaction barriers and pre-exponential factors that increase with oxidative stress (AngII < AngII $+\mathrm{O}<$ AngII $+3 \mathrm{O} /$ AngII $+4 \mathrm{O}$ ). Thus the threshold behavior is controlled by the pre-exponential 
factors, which in turn depend on the entropies of activation. These results indicate that the primary reaction channels require significant conformational rearrangement in the formation of the transition states for each reaction pathway. Molecular dynamics calculations suggest reaction pathways involving hydrogen-bonded, closed-ring structures accounting for the importance of entropy in controlling the unimolecular kinetics of decomposition. Comparison between results for cleavage C-terminal to aspartic acid $\left(\mathbf{y}_{7}\right)$ in unmodified angiotensin II and the selective charge-remote $\mathbf{b}_{\mathbf{4}}+\mathbf{O}$ dissociation pathway involving oxidized Tyr* (AngII $+\mathrm{O})$ suggests intramolecular salt bridge interactions are unnecessary for chargeremote fragmentation involving acidic amino acid residues.

\section{Acknowledgments}

The authors acknowledge financial support to JS provided by the Summer Research Institute in Interfacial and Condensed Phase Chemical Physics at Pacific Northwest National Laboratory (PNNL), and by the NSF Graduate Teaching Fellows Program in K-12 Education (DGE 0538555), NSF grant no. CHE-0098831 to MVJ, and NSF grant no. 0541775 to the University of Delaware to update FT-MS equipment. FT-ICR MS and energetic experiments were conducted at the W. R. Wiley Environmental Molecular Sciences Laboratory (EMSL), a national scientific user facility sponsored by the U.S. Department of Energy, located at PNNL. The facility is operated by Battelle for the U.S. Department of Energy. Research at EMSL was carried out within project 40457 supported by the Office of Basic Energy Sciences of the U.S. Department of Energy.

\section{References}

1. Bosson, J.; Barath, S.; Pourazar, J.; Behndig, A. F.; Sandstroem, T.; Blomberg, A.; Aedelroth, E. Diesel Exhaust Exposure Enhances the Ozone-Induced Airway Inflammation in Healthy Humans. Eur. Respir. J. 2008, 31, 1234-1240

2. Iriti, M.; Faoro, F. Oxidative Stress, the Paradigm of Ozone Toxicity in Plants and Animals. Water, Air, Soil Pollut. 2008, 187, 285-301.

3. Tzortzakis, N.; Singleton, I.; Barnes, J. Impact of Low-Level Atmospheric Ozone-Enrichment on Black Spot and Anthracnose Rot of Tomato Fruit. Postharvest Biol. Technol. 2008, 47, 1-9.

4. Burkey, K. O.; Booker, F. L.; Pursley, W. A.; Heagle, A. S. Elevated Carbon Dioxide and Ozone Effects on Peanut: II. Seed Yield and Quality. Crop. Sci. 2007, 47, 1488-1497.

5. Chen, C.; Arjomandi, M.; Balmes, J.; Tager, I.; Holland, N. Effects of Chronic and Acute Ozone Exposure on Lipid Peroxidation and Antioxidant Capacity in Healthy Young Adults. Environ. Health Perspect. 2007, 115, 1732-1737.

6. Chuang, K.; Chan, C.; Su, T.; Lee, C.; Tang, C. The Effect of Urban Air Pollution on Inflammation, Oxidative Stress, Coagulation, and Autonomic Dysfunction in Young Adults. Am. J. Respir. Crit. Care Med. 2007, $176,370-376$

7. Hollingsworth, J. W.; Maruoka, S.; Li, Z.; Potts, E. N.; Brass, D. M.; Garantziotis, S.; Fong, A.; Foster, W. M.; Schwartz, D. A. Ambient Ozone Primes Pulmonary Innate Immunity in Mice. J. Immunol. 2007, 179, 4367-4375.

8. Leitao, L.; Bethenod, O.; Biolley, J. The Impact of Ozone on Juvenile Maize (Zea Mays L.) Plant Photosynthesis: Effects on Vegetative Biomass, Pigmentation, and Carboxylases (PEPc and Rubisco). Plant Biol. (Stuttgart, Germany). 2007, 9, 478-488.

9. Zou, Z.; Liu, Y.; Wu, Y.; Li, Q.; Chen, M.; Sun, H.; Lee, I. SurfaceEnhanced Raman Spectra of Oxidation Damage of Fetal Bovine Serum by Ozone. Guangpuxue Yu Guangpu Fenxi 2007, 27, 1140-1142.

10. Chen, C.; Arjomandi, M.; Qin, H.; Balmes, J.; Tager, I.; Holland, N. Cytogenetic Damage in Buccal Epithelia and Peripheral Lymphocytes of Young Healthy Individuals Exposed to Ozone. Mutagenesis 2006, 21, 131-137.

11. Cataldo, F. On the Action of Ozone on Proteins. Polym. Degrad. Stab. 2003, 82, 105-114.

12. Ashmore, M. R.; Marshall, F. M. Ozone Impacts on Agriculture: An Issue of Global Concern. Adv. Bot. Res. 1999, 29, 31-52.
13. Dell'era, R.; Brambilla, E.; Ballarin-Denti, A. Ozone and Air Particulate Measurements in Mountain Forest Sites. Chemosphere 1998, 36, 1083 1088.

14. Mudd, J. B.; Dawson, P. J.; Tseng, S.; Liu, F. Reaction of Ozone with Protein Tryptophans: Band III, Serum Albumin, and Cytochrome $c$. Arch. Biochem. Biophys. 1997, 338, 143-149.

15. Berlett, B. S.; Levine, R. L.; Stadtman, E. R. Comparison of the Effects of Ozone on the Modification of Amino Acid Residues in Glutamine Synthetase and Bovine Serum Albumin. J. Biol. Chem. 1996, 271, 41774182 .

16. Mudd, J. B.; Dawson, P. J.; Adams, J. R.; Wingo, J.; Santrock, J. Reaction of Ozone with Enzymes of Erythrocyte Membranes. Arch. Biochem. Biophys. 1996, 335, 145-151.

17. Uppu, R. M.; Cueto, R.; Squadrito, G. L.; Pryor, W. A. What does Ozone React with at the Air/Lung Interface? Model Studies Using Human Red Blood Cell Membranes. Arch. Biochem. Biophys. 1995, 319, 257-266.

18. Weisel, C. P.; Cody, R. P.; Lioy, P. J. Relationship between Summertime Ambient Ozone Levels and Emergency Department Visits for Asthma in Central New Jersey. Environ. Health Perspect. 1995, 103(Suppl 2), 97-102.

19. Schmut, O.; Gruber, E.; el-Shabrawi, Y.; Faulborn, J. Destruction of Human Tear Proteins by Ozone. Free Radic. Biol. Med. 1994, 17, 165-169.

20. Uppu, R. M.; Pryor, W. A. The Reactions of Ozone with Proteins and Unsaturated Fatty Acids in Reverse Micelles. Chem. Res. Toxicol. 1994, 7 , 47-55.

21. O'Neill, C. A.; van der Vliet, A.; Hu, M. L.; Kaur, H.; Cross, C. E.; Louie S.; Halliwell, B. Oxidation of Biologic Molecules by Ozone: The Effect of pH. J. Lab. Clin. Med. 1993, 122, 497-505.

22. Pryor, W. A.; Uppu, R. M. A Kinetic Model for the Competitive Reactions of Ozone with Amino Acid Residues in Proteins in Reverse Micelles. J. Biol. Chem. 1993, 268, 3120-3126.

23. Kanofsky, J. R.; Sima, P. Singlet Oxygen Production from the Reactions of Ozone with Biological Molecules. J. Biol. Chem. 1991, 266, 9039-9042.

24. Knight, K. L.; Mudd, J. B. The Reaction of Ozone with Glyceraldehyde3-Phosphate Dehydrogenase. Arch. Biochem. Biophys. 1984, 229, 259-269.

25. Menzel, D. B. Ozone: An Overview of its Toxicity in Man and Animals. J. Toxicol. Environ. Health 1984, 13, 183-204.

26. Dooley, M. M.; Mudd, J. B. Reaction of Ozone with Lysozyme Under Different Exposure Conditions. Arch. Biochem. Biophys. 1982, 218, 459 471.

27. Kuroda, M.; Sakiyama, F.; Narita, K. Oxidation of Tryptophan in Lysozyme by Ozone in Aqueous Solution. J. Biochem. (Tokyo, Japan). $1975,78,641-651$.

28. Kotiaho, T.; Eberlin, M. N.; Vainiotalo, P.; Kostiainen, R. Electrospray Mass and Tandem Mass Spectrometry Identification of Ozone Oxidation Products of Amino Acids and Small Peptides. J. Am. Soc. Mass Spectrom. 2000, 11, 526-535.

29. Pryor, W. A.; Giamalva, D. H.; Church, D. F. Kinetics of Ozonation. 2. Amino Acids and Model Compounds in Water and Comparisons to Rates in Nonpolar Solvents. J. Am. Chem. Soc. 1984, 106, 7094-7100.

30. Mudd, J. B.; Leavitt, R.; Ongun, A.; McManus, T. T. Reaction of Ozone with Amino Acids and Proteins. (1967-1989). At. Environ. 1969, 3 , 669-682.

31. Previero, A.; Scoffone, E.; Benassi, C. A.; Pajetta, P. Investigations on the Structure of Proteins. XI. Modification of the Tryptophan Residue in a Peptide Chain. Gazzetta Chim. Ital. 1963, 93, 849-858.

32. Previero, A.; Scoffone, E.; Pajetta, P.; Benassi, C. A. The Structure of Proteins. X. the Behavior of Amino Acids in the Presence of Ozone. Gazzetta Chim. Ital. 1963, 93, 841-848.

33. Lloyd, J. A.; Spraggins, J. M.; Johnston, M. V.; Laskin, J. Peptide Ozonolysis: Product Structures and Relative Reactivities for Oxidation of Tyrosine and Histidine Residues. J. Am. Soc. Mass Spectrom. 2006, 17, $1289-1298$

34. Summerfield, S. G.; Gaskell, S. J. Fragmentation Efficiencies of Peptide Ions Following Low Energy Collisional Activation. Int. J. Mass Spectrom. Ion Processes 1997, 165/166, 509-521.

35. Kamal, J. K. A.; Benchaar, S. A.; Takamoto, K.; Reisler, E.; Chance, M. R Three-Dimensional Structure of Cofilin Bound to Monomeric Actin Derived by Structural Mass Spectrometry Data. Proc. Natl. Acad. Sci. U.S.A. 2007, 104, 7910-7915.

36. Kiselar, J. G.; Mahaffy, R.; Pollard, T. D.; Almo, S. C.; Chance, M. R. Visualizing Arp2/3 Complex Activation Mediated by Binding of ATP and WASp using Structural Mass Spectrometry. Proc. Natl. Acad. Sci. U.S.A. 2007, 104, 1552-1557, S1552/1-S1552/2.

37. Takamoto, K.; Chance, M. R. Radiolytic Protein Footprinting with Mass Spectrometry to Probe the Structure of Macromolecular Complexes. Annu. Rev. Biophys. Biomol. Struct. 2006, 35, 251-276.

38. Aye, T. T.; Low, T. Y.; Sze, S. K. Nanosecond Laser-Induced Photochemical Oxidation Method for Protein Surface Mapping with Mass Spectrometry. Anal. Chem. 2005, 77, 5814-5822.

39. Guan, J.; Chance, M. R. Structural Proteomics of Macromolecular Assemblies Using Oxidative Footprinting and Mass Spectrometry. Trends Biochem. Sci. 2005, 30, 583-592.

40. Hambly, D. M.; Gross, M. L. Laser Flash Photolysis of Hydrogen Peroxide to Oxidize Protein Solvent-Accessible Residues on the Microsecond Timescale. J. Am. Soc. Mass Spectrom. 2005, 16, 2057-2063.

41. Sharp, J. S.; Guo, J.; Uchiki, T.; Xu, Y.; Dealwis, C.; Hettich, R. L. Photochemical Surface Mapping of C14S-Sml1p for Constrained Computational Modeling of Protein Structure. Anal. Biochem. 2005, 340, 201-212. 
42. Guan, J.; Almo, S. C.; Chance, M. R. Synchrotron Radiolysis and Mass Spectrometry: A New Approach to Research on the Actin Cytoskeleton. Acc. Chem. Res. 2004, 37, 221-229.

43. Sharp, J. S.; Becker, J. M.; Hettich, R. L. Analysis of Protein Solvent Accessible Surfaces by Photochemical Oxidation and Mass Spectrometry. Anal. Chem. 2004, 76, 672-683.

44. Kiselar, J. G.; Maleknia, S. D.; Sullivan, M.; Downard, K. M.; Chance, M. R. Hydroxyl Radical Probe of Protein Surfaces using Synchrotron X-Ray Radiolysis and Mass Spectrometry. Int. J. Radiat. Biol. 2002, 78, 101-114

45. Maleknia, S. D.; Downard, K. M. Radical Approaches to Probe Protein Structure, Folding, and Interactions by Mass Spectrometry. Mass Spectrom. Rev. 2002, 20, 388-401.

46. Maleknia, S. D.; Kiselar, J. G.; Downard, K. M. Hydroxyl Radical Probe of the Surface of Lysozyme by Synchrotron Radiolysis and Mass Spectrometry. Rapid Commun. Mass Spectrom. 2002, 16, 53-61.

47. Chance, M. R. Unfolding of Apomyoglobin Examined by Synchrotron Footprinting. Biochem. Biophys. Res. Commun. 2001, 287, 614-621.

48. Laskin, J. Energetics and Dynamics of Peptide Fragmentation from Multiple-Collision Activation and Surface-Induced Dissociation Studies. Eur. J. Mass Spectrom. 2004, 10, 259-267.

49. Laskin, J.; Yang, Z.; Chu, I. K. Energetics and Dynamics of Electron Transfer and Proton Transfer in Dissociation of MetalIII(Salen)-Peptide Complexes in the Gas Phase. J. Am. Chem. Soc. 2008, 130, 3218-3230.

50. Yang, Z.; Lam, C.; Chu, I. K.; Laskin, J. The Effect of the Secondary Structure on Dissociation of Peptide Radical Cations: Fragmentation of Angiotensin III and its Analogues. J Phys. Chem. B 2008, 112, 1246812478.

51. Lioe, H.; Laskin, J.; Reid, G. E.; O’Hair, R. A. J. Energetics and Dynamics of the Fragmentation Reactions of Protonated Peptides Containing Methionine Sulfoxide Or Aspartic Acid Via Energy- and Time-Resolved Surface Induced Dissociation. J. Phys. Chem. A 2007, 111, 10580-10588.

52. Laskin, J. Energetics and Dynamics of Fragmentation of Protonated Leucine Enkephalin from Time- and Energy-Resolved Surface-Induced Dissociation Studies. J. Phys. Chem. A 2006, 110, 8554-8562.

53. Laskin, J.; Bailey, T. H.; Futrell, J. H. Mechanisms of Peptide Fragmentation from Time- and Energy-Resolved Surface-Induced Dissociation Studies: Dissociation of Angiotensin Analogs. Int. J. Mass Spectrom. 2006, 249/250, 462-472.

54. Laskin, J. Energetics and Dynamics of Peptide Fragmentation from Multiple-Collision Activation and Surface-Induced Dissociation Studies. Eur. J. Mass Spectrom. 2004, 10, 259-267.

55. Laskin, J.; Bailey, T. H.; Futrell, J. H. Fragmentation Energetics for Angiotensin II and its Analogs from Time- and Energy-Resolved Surface-Induced Dissociation Studies. Int. J. Mass Spectrom. 2004, 234, 89-99.

56. Bailey, T. H.; Laskin, J.; Futrell, J. H. Energetics of Selective Cleavage at Acidic Residues Studied by Time- and Energy-Resolved SurfaceInduced Dissociation in FT-ICR MS. Int. J. Mass Spectrom. 2003, 222, 313-327.

57. Laskin, J.; Bailey, T. H.; Futrell, J. H. Shattering of Peptide Ions on Self-Assembled Monolayer Surfaces. J. Am. Chem. Soc. 2003, 125, 16251632.

58. Laskin, J.; Futrell, J. H. Surface-Induced Dissociation of Peptide Ions: Kinetics and Dynamics. J. Am. Soc. Mass Spectrom. 2003, 14, 1340-1347.
59. Laskin, J.; Bailey, T. H.; Denisov, E. V.; Futrell, J. H. On the Relative Stability of Singly Protonated Des-Arg1- and Des-Arg9-Bradykinins. J. Phys. Chem. A 2002, 106, 9832-9836.

60. Shaffer, S. A.; Tang, K.; Anderson, G. A.; Prior, D. C.; Udseth, H. R. Smith, R. D. A Novel Ion Funnel for Focusing Ions at Elevated Pressure using Electrospray Ionization Mass Spectrometry. Rapid Commun. Mass Spectrom. 1997, 11, 1813-1817.

61. Laskin, J.; Denisov, E. V.; Shukla, A. K.; Barlow, S. E.; Futrell, J. H Surface-Induced Dissociation in a Fourier Transform Ion Cyclotron Resonance Mass Spectrometer: Instrument Design and Evaluation. Anal. Chem. 2002, 74, 3255-3261.

62. Laskin, J.; Byrd, M.; Futrell, J. Internal Energy Distributions Resulting from Sustained Off-Resonance Excitation in FTMS. I. Fragmentation of the Bromobenzene Radical Cation. Int. J. Mass Spectrom. 2000, 195/196, 285-302.

63. Laskin, J.; Futrell, J. Internal Energy Distributions Resulting from Sustained Off-Resonance Excitation in Fourier Transform Ion Cyclotron Resonance Mass Spectrometry. II. Fragmentation of the 1Bromonaphthalene Radical Cation. J. Phys. Chem. A 2000, 104, 5484-5494.

64. Derrick, P. J.; Lloyd, P. M.; Christie, J. R. Physical Chemistry of Ion Reactions. Adv. Mass Spectrom. 1995, 13, 23-52.

65. Tsaprailis, G.; Somogyi, A.; Nikolaev, E. N.; Wysocki, V. H. Refining the Model for Selective Cleavage at Acidic Residues in Arginine-Containing Protonated Peptides. Int. J. Mass Spectrom. 2000, 195/196, 467-479.

66. Tsaprailis, G.; Nair, H.; Somogyi, A.; Wysocki, V. H.; Zhong, W.; Futrell, J. H.; Summerfield, S. G.; Gaskell, S. J. Influence of Secondary Structure on the Fragmentation of Protonated Peptides. J. Am. Chem. Soc. 1999, 121, 5142-5154.

67. Herrmann, K. A.; Wysocki, V. H.; Vorpagel, E. R. Computational Investigation and Hydrogen/Deuterium Exchange of the Fixed Charge Derivative Tris(2,4,6-Trimethoxyphenyl) Phosphonium: Implications for the Aspartic Acid Cleavage Mechanism. J. Am. Soc. Mass Spectrom. 2005, 16, 1067-1080.

68. Gu, C.; Tsaprailis, G.; Breci, L.; Wysocki, V. H. Selective Gas-Phase Cleavage at the Peptide Bond C-Terminal to Aspartic Acid in FixedCharge Derivatives of Asp-Containing Peptides. Anal. Chem. 2000, 72, $5804-5813$

69. Lee, S.; Kim, H. S.; Beauchamp, J. L. Salt Bridge Chemistry Applied to Gas-Phase Peptide Sequencing: Selective Fragmentation of Sodiated Gas-Phase Peptide Ions Adjacent to Aspartic Acid Residues. J. Am. Chem. Soc. 1998, 120, 3188-3195.

70. Summerfield, S. G.; Whiting, A.; Gaskell, S. J. Intraionic Interactions in Electrosprayed Peptide Ions. Int. J. Mass Spectrom. Ion Processes 1997 $162,149-161$

71. Yu, W.; Vath, J. E.; Huberty, M. C.; Martin, S. A. Identification of the Facile Gas-Phase Cleavage of the Asp-Pro and Asp-Xxx Peptide Bonds in Matrix-Assisted Laser Desorption Time-of-Flight Mass Spectrometry. Anal. Chem. 1993, 65, 3015-3023.

72. Yalcin, T.; Khouw, C.; Csizmadia, I. G.; Peterson, M. R.; Harrison, A. G. Why are B Ions Stable Species in Peptide Spectra? J. Am. Soc. Mass Spectrom. 1995, 6, 1165-1174

73. Dongre, A. R.; Jones, J. L.; Somogyi, A.; Wysocki, V. H. Influence of Peptide Composition, Gas-Phase Basicity, and Chemical Modification on Fragmentation Efficiency: Evidence for the Mobile Proton Model. J. Am. Chem. Soc. 1996, 118, 8365-8374. 